\title{
END TIDAL CARBON DIOXIDE LEVELS DURING THE RESUSCITATION OF PREMATURELY BORN INFANTS
}

\author{
V. Murthy ${ }^{1}$, A. O'Rourke ${ }^{1}$, G.F. Fox ${ }^{2}$, M.E. Campbell ${ }^{2}$, A. Milner ${ }^{1}$, A. Greenough ${ }^{1}$ \\ ${ }^{1}$ Division of Asthma, Allergy and Lung Biology, King's College London, ${ }^{2}$ Newborn Unit, Evelina Children's \\ Hospital Neonatal Unit, St Thomas' Hospital, London, UK
}

Background and aims: To test the hypothesis that effective ventilation, as evidenced by an increase in expired carbon dioxide $\left(\mathrm{CO}_{2}\right)$, during the initial resuscitation of prematurely born infants would only occur when the infants made inspiratory efforts.

Methods: A respiratory function monitor (NM3, Respironics) and a computer laptop with recording and analysis software (Spectra, Groove medical, UK) were used to collect and analyse air flow, airway pressure, tidal volume and expired carbon dioxide levels $\left(\mathrm{PetCO}_{2}\right)$ changes during the first five inflations at resuscitation of infants born before 34 weeks of gestation. Inflations were divided in to those in which the infant inspired (active inflations) and those without inspiratory efforts (passive inflations). The study was approved by Outer North London ethics committee and parental consent was obtained for analysis of the data.

Results: Forty prematurely born infants (median gestational age of 30 weeks and birthweight of 1226gms) were included in the study. The median (IQR) $\mathrm{PetCO}_{2}$ levels during the first five inflations was $0.3(0.1-2.1)$ kpa. $\mathrm{PetCO}_{2}$ levels were higher following active [3.7kpa (2.4-5.4)] compared to passive [0.1 kpa(0-0.8)] inflations $(\mathrm{p}<0.01)$. The median $(\mathrm{IQR}) \mathrm{PetCO}_{2}$ levels before, during and after the first inspiratory effort were $0.2 \mathrm{kpa}(0.1-0.5), 3.5 \mathrm{kpa}(1.5-5.4)$ and $2.8 \mathrm{kpa}(0.9-4.9)$ respectively $(\mathrm{p}<0.01)$.

Conclusions: These results suggest that $\mathrm{CO}_{2}$ clearance is enhanced if prematurely born infants are stimulated to breathe during resuscitation. 